\title{
Weather Index Insurance and Climate Change: Opportunities and Challenges in Lower Income Countries
}

\author{
Benjamin Collier ${ }^{\mathrm{a}}$, Jerry Skees ${ }^{\mathrm{a}}$ and Barry Barnett ${ }^{\mathrm{b}}$ \\ ${ }^{a}$ Agricultural Economics, University of Kentucky, 1008 S. Broadway, Lexington, KY 40504, U.S.A. \\ ${ }^{\mathrm{b}}$ Agricultural Economics, Mississippi State University, Starkville, MS, U.S.A.
}

Weather index insurance underwrites a weather risk, typically highly correlated with agricultural production losses, as a proxy for economic loss and is gaining popularity in lower income countries. This instrument, although subject to basis risk and high start-up costs, should reduce costs over traditional agricultural insurance. Multilateral institutions have suggested that weather index insurance could enhance the ability of stakeholders in lower income countries to adapt to climate change. While weather index insurance could have several benefits in this context (e.g. providing a safety net to vulnerable households and price signals regarding the weather risk), climate change impacts increase the price of insurance due to increasing weather risk. Uncertainty about the extent of regional impacts compounds pricing difficulties. Policy recommendations for insurance market development include funding risk assessments, start-up costs and the extreme layer of risk. General premium subsidies are cautioned against as they may actually slow household adaptation.

The Geneva Papers (2009) 34, 401-424. doi:10.1057/gpp.2009.11

Keywords: weather index insurance; agricultural insurance; climate change adaptation; financial services development; lower income countries

\section{Introduction}

This paper is motivated by the calls of multilateral institutions such as the United Nations Framework Convention on Climate Change (UNFCCC) and the Intergovernmental Panel on Climate Change to support insurance markets as a means of increasing resilience against climate change impacts in lower income countries. For example, Article 4.8 of the UNFCCC states:

The Parties shall give full consideration to what actions are necessary under the Convention, including actions related to funding, insurance and the transfer of technology, to meet the specific needs and concerns of developing country Parties arising from the adverse effects of climate change ...

Our purpose is to explore the thesis that weather index insurance can play an important role in climate change adaptation for households in lower income 
countries. ${ }^{1}$ Insurance is commonly used to motivate adaptation; however, as will be developed, climate change creates significant problems for weather index insurance that complicate how governments or donors choose to support the development of these markets. Thus, we intend to contribute to the ongoing debate about how to best support insurance in lower income countries.

Climate change adaptation is intrinsically tied to development issues in lower income countries. The least developed countries, which have economies largely dependent on agriculture, limited social safety nets and very little risk mitigation infrastructure, are the most vulnerable countries to climate change. ${ }^{2}$ Likewise, the poor, who live and work on marginal lands, engage in unskilled labour, and have very limited access to capital, are the most vulnerable populations to climate change. ${ }^{3}$ Furthermore, the risk of catastrophic weather shocks contributes to trapping poor households into chronic poverty. ${ }^{4}$ Climate change is likely to increase the frequency of these weather shocks in many regions of the world. ${ }^{5}$

Recent articles have highlighted how donors could support insurance for lower income countries to facilitate adaptation to climate change. ${ }^{6}$ Many of these macrooriented articles focus on creating global public support for ex ante financing of insurance to pay for what are expected to be greater losses in the future. While this is clearly an important consideration, it is equally important to understand more of the micro-level details regarding insurance and climate change.

We begin this paper by reviewing the economic underpinnings of insurance purchasing decisions and the benefits of insurance in an economic development context. Our focus is on a special form of agricultural insurance because agriculture is the most prevalent livelihood in lower income countries and is particularly vulnerable to climate change. The 2008 World Development Report ${ }^{7}$ states that 2.5 billion people in lower income countries are "in households involved in agriculture". We profile weather index insurance, an innovative insurance product that is creating firsttime access to agricultural insurance for households in some lower income countries. Weather index insurance has primarily been used in the context of agriculture as its structure avoids many of the difficulties of traditional forms of agricultural insurance. After explaining the potential of weather index insurance, we explore the challenges and opportunities that climate change presents for this form of insurance. Weather index insurance is particularly relevant to climate change because it insures against weather risks. Climate change adaptation is likely to require a variety of investments;

\footnotetext{
${ }^{1}$ Smallholder households predominate in lower income countries and are, therefore, the primary focus of this paper. We do not distinguish between subsistence farmers and commercial farmers who tend to sell their commodities; however, farmer characteristics have specific implications for designing appropriate risk management strategies (see Skees and Collier, 2008). Because the relative merits of risk management strategies must be assessed given the particular characteristics of a target population, generalisations to other vulnerable populations such as the landless poor should be conducted with care.

${ }^{2}$ Carter et al. (2007); Morton (2007); Stern (2006).

${ }^{3}$ Nicholls et al. (2007); Corbera et al. (2006).

${ }^{4}$ For example, Barnett et al. (2008); Sachs and Arthur (2005).

${ }^{5}$ IPCC (2007); Morton (2007); Corbera et al. (2006).

${ }^{6}$ For example, Linnerooth-Bayer et al. (2007).

${ }^{7}$ World Bank (2008).
} 
prioritising these investments is enhanced by research through risk assessments to estimate what effect climate change impacts may have on local stakeholders. Weather index insurance provides several potential benefits that enhance household adaptation to climate change; however, climate change impacts also create difficulties for pricing weather index insurance. In regions where climate change results in increasing weather risk, insurance prices must also increase, in some cases to an extent that is likely costprohibitive to households. Finally, we provide policy recommendations for those interested in supporting insurance market development as a mechanism to facilitate adaptation. Government and donor investments are likely to be most effective in funding risk assessments and market development start-up costs. Government support in the form of premium subsidies where the government pays a fixed portion of total insurance premiums may actually impede adaptation by encouraging households to maintain or increase investments in unsustainable livelihoods. A less distorting structure of ongoing government support is to divide the risk into a moderately severe commercial layer and an extremely severe social layer. Whatever investments governments and donors make to support insurance markets should be carefully considered in light of their opportunity costs as adaptation needs far outweigh current funding levels.

\section{Farmer portfolios and insurance}

Farm households manage portfolios of assets from which they hope to generate net returns. For farmers in lower income countries, those assets have often been acquired at very high opportunity cost in the form of foregone consumption. While some farmers invest in financial assets such as savings accounts, this choice is generally not available in rural areas of lower income countries. ${ }^{8}$ Instead, farmers tend to invest in assets such as livestock, farm and household tools, equipment, fertiliser, perennial crops and the human capital of family members (e.g. education, immunisations, etc).

Consider a farmer who manages a portfolio of $n$ assets. Each asset $A_{i}(i=1,2, \ldots, n)$ generates a stochastic periodic net return $r_{i}$ such that the net return on the entire portfolio of assets $R$ is $R=\sum_{i=1}^{n} w_{i} r_{i}$, where $w_{i}$ is the proportion of the total value of the portfolio that is invested in $A_{i}$ and $\sum_{i=1}^{n} w_{i}=1$.

The risk of the portfolio (measured as the variance of returns) is calculated as $\sigma_{R}^{2}=\sum_{j=1}^{n} \sum_{k=1}^{n} w_{j} w_{k} \sigma_{j k}^{2}$, where $\sigma_{j k}^{2}$ is the variance in returns on the single asset when $j=k$ and the pairwise covariance in returns when $j \neq k$ with $\sum_{j=1}^{n} w_{j}=1$ and $\sum_{k=1}^{n} w_{k}=1$.

The farmer maximises a generalised expected utility function defined over the distribution of $R$ and subject to relevant constraints, with $\partial E(U) / \partial E(R)>0$ and $\partial E(U) /$ $\partial \sigma_{R}^{2}<0 .{ }^{9}$ If the farmer purchases insurance, the insurance policy is simply another

\footnotetext{
${ }^{8}$ McPeak and Barrett (2001); Dercon (1998); Besley (1995).

${ }^{9}$ For ease of exposition, a generalised conceptual model is presented here rather than a model that specifies functional relationships. Also, the model is static whereas a more mathematically complex temporal model would allow for investment in, and liquidation of, assets. The generalised static model is sufficient to motivate a discussion of how insurance purchasing affects household behaviour. More detailed and complex expected utility models of rural household decision making under conditions of risk can be found in Rosenzweig and Binswanger (1993); Rosenzweig and Wolpin (1993) and de Janvry et al. (1991).
} 
asset in the portfolio. ${ }^{10}$ Insurance purchasing will decrease both $E(R)$ and $\sigma_{R}^{2} . E(R)$ decreases because the insurance premium will not be actuarially fair - that is, $E\left(R_{\text {insurance }}\right)<0$. As described below, the insurer will load the insurance premium to cover various expenses (information collection and processing, delivery, loss adjustment, risk financing, etc.) and to provide a competitive return on equity. The variance of net returns $\sigma_{R}^{2}$ will decrease because, by design, returns from the insurance policy are negatively correlated with returns from at least one other asset in the portfolio. Only farmers who are risk-averse (i.e., utility is decreasing in $\sigma_{R}^{2}$ ) would purchase typical insurance policies for which $E\left(R_{\text {insurance }}\right)<0$.

In lower income countries, the variance of net returns $\sigma_{R}^{2}$ for farmers without insurance is often high due to underdeveloped risk mitigation infrastructure (e.g. levies, irrigation); limited access to the agricultural value chain (e.g. for improvedtechnology inputs), and high covariance in returns $r_{i}$ among portfolio assets since the returns on most assets are dependent on agricultural outcomes in the community. In years when catastrophic weather events occur (e.g. drought), the covariance among returns may be even higher because the whole rural economy experiences the shock smallholder farmers experience yield losses, labour demand (e.g. for harvest) on larger farms is reduced, and decreased wealth decreases demand for goods from firms serving the local market.

Because of this high variability of net returns, agricultural insurance - especially for catastrophic risks - can be an important tool for rural economic development. Farmers, who would otherwise be reluctant to invest in assets or engage in livelihood strategies that involve higher expected return but also greater risk exposure, are more likely to consider such alternatives if the risk exposure can be transferred to other parties via insurance. ${ }^{11}$

\section{Weather index insurance in lower income countries}

Weather index insurance is gaining increased attention as a potentially sustainable market mechanism to transfer weather risk in lower income countries. Experience had led some researchers to conclude that traditional agricultural insurance markets such as for multiple peril crop insurance (MPCI) are a very poor and often unsustainable investment in lower income countries due to the preponderance of small farms as well as the typical asymmetric information problems. ${ }^{12}$ Weather index insurance presents a promising alternative to traditional agricultural insurance for many lower income countries. Weather index insurance insures against a weather event that is highly correlated with production loss as a proxy for individual loss. ${ }^{13}$ For example, one of the first weather index insurance programmes in a lower income country began in

\footnotetext{
${ }^{10}$ The insurance may protect against decreased revenue (e.g. crop yield or revenue insurance) or increased expenses (e.g. health insurance) associated with one or more assets in the portfolio. Alternatively, it may protect against the actual loss of one or more assets (e.g. property or life insurance).

${ }^{11}$ Barnett et al. (2008).

${ }^{12}$ For example, Hazell (1992).

${ }^{13}$ Barnett and Mahul (2007); Hazell and Skees (2006).
} 
India and insured against drought for groundnut farmers as assessed by rainfall measurements. ${ }^{14}$ Indemnities are based on measurements of an objective third-party index, for example, a specific weather parameter measured over a pre-specified period of time at a particular weather station. Weather index insurance is typically written for a single peril, the weather risk of greatest concern to production. As a result of its structure, weather index insurance avoids many of the activities that make MPCI so expensive to administer - collecting farm-level yield data, controlling for moral hazard and adverse selection, and conducting individualised loss assessments creating opportunities to insure crop or livestock enterprises which might otherwise be too expensive to insure.

In terms of development, weather index insurance products are generally most effective when targeted to protect against catastrophic weather events. The risk management strategies of farm households, including labour and crop diversification, risk-sharing reciprocal relationships of community members and distressed sale of assets, break down when weather shocks result in correlated losses. The poverty traps literature provides strong theoretical arguments and data that lend support to the hypothesis that uninsured, poor households sustain long-term and often irreparable consequences as a result of a catastrophic event. ${ }^{15}$ Thus, weather index insurance fits into a broader financial services development framework that complements recent advancements in microcredit and savings. ${ }^{16}$

\section{Basis risk}

The most challenging disadvantage of weather index insurance is basis risk, which is variability in the relationship between the value of losses as measured by the index and the value of losses experienced on the farm. Basis risk occurs due to spatial variation in weather variables (particularly where there are local micro-climates) as well as differences in management practices, soil quality or crop varieties. Because no individualised loss adjustment occurs with weather index insurance, the policy-holder must always carry the basis risk.

Careful insurance product design can reduce (but not eliminate) basis risk. In particular, it is important that the index reflects spatially correlated loss events such as drought or extreme temperatures. Additionally, basis risk should be lowest when weather index insurance is specifically designed to protect against catastrophic loss events; however, households tend to exhibit a cognitive failure: they tend to underestimate the likelihood of catastrophic events and fail to adequately prepare for them. ${ }^{17}$ Thus, designing a weather index insurance contract requires a balance between minimising basis risk and meeting customer demand for insurance that protects against more than catastrophic events.

\footnotetext{
${ }^{14}$ Hess (2003).

15 Barnett et al. (2008); Carter et al. (2005, 2006).

16 Skees and Barnett (2006).

${ }^{17}$ Buzby (1994); Rossi et al. (1982); Kunreuther and Slovic (1978); Kunreuther (1976).
} 


\section{Pricing weather index insurance}

Despite cost benefits over MPCI, creating weather index insurance products at prices that are accessible to smallholders remains a significant challenge. Decomposing the specific components of weather index insurance pricing will facilitate our discussion of how climate change impacts affect weather index insurance. The following equation gives a simple breakdown of the costs that factor into the price of weather index insurance:

$$
\begin{aligned}
\text { Price }= & \text { Cost of the Risk }+ \text { Risk Loading Costs } \\
& + \text { Administrative Costs }+ \text { Cost of Ready Access to Capital }
\end{aligned}
$$

\section{Cost of the risk}

Estimating the "pure" risk is often difficult when pricing weather index insurance because of the lack of data in lower income countries. Weather data are used to develop a probability distribution of the underlying weather variable. Triggers and pay-out rates are chosen based on previous catastrophic events and their effects on, for example, crop growth, household livelihoods, or loan defaults, depending on the needs of the target market. From these estimates, actuaries determine the pure risk (the expected loss cost) of the insurance contract.

Martin et al. $^{18}$ and Vedenov and Barnett ${ }^{19}$ define generalised linear indemnity functions for weather index insurance contracts. If the contract protects against insufficient realisations of the underlying cumulative weather variable (e.g. insufficient cumulative precipitation), the indemnity function is

$$
\text { indemnity }=f\left(i \mid x, i^{*}, \lambda\right)=x \times \begin{cases}0 & \text { if } i>i^{*} \\ \frac{i^{*}-i}{i^{*}-\lambda i^{*}} & \text { if } \lambda i^{*}<i \leqslant i^{*} \\ 1 & \text { if } i \leqslant \lambda i^{*}\end{cases}
$$

where $i$ is the realised value of the underlying weather variable, $x$ is the sum insured, $i^{*}$ is the trigger, and $\lambda$ is a variable that defines the limit (the level of the underlying variable for which the maximum indemnity is paid) in proportion to the trigger with $0<\lambda \leqslant 1$. If the realised value is less than the trigger but greater than the limit $\left(\lambda i^{*}<i<i^{*}\right)$, the indemnity is proportional to the difference between the trigger and the limit. No indemnity is paid if the realised value is greater than or equal to the trigger $\left(i \geqslant i^{*}\right)$. The maximum indemnity (equal to the full sum insured) is paid if the realised value is less than or equal to the limit $\left(i \leqslant \lambda i^{*}\right)$. Thus, the selection of $\lambda$ determines how quickly the maximum indemnity is reached after an indemnity is triggered. As an extreme example if $\lambda=1$, then any value below the threshold receives a full indemnity and the middle equation $i^{*}-i / i^{*}-\lambda i^{*}$ is not used. The contract is fully specified by the insured's three choice variables $x, i^{*}$, and $\lambda$. $^{20}$

\footnotetext{
18 Martin et al. (2001).

19 Vedenov and Barnett (2004).

${ }^{20}$ While this indemnity function is linear, Vedenov and Barnett (2004) describe how a non-linear indemnity function can be approximated by combining contracts with different values of $x, i^{*}$ and $\lambda$.
} 
For a contract that protects against excessive realisations of the underlying cumulative weather variable (e.g. excessive cumulative heating degree days), the indemnity function is

$$
\text { indemnity }=f\left(i \mid x, i^{*}, \lambda\right)=x \times \begin{cases}1 & \text { if } i \geqslant \lambda i^{*} \\ \frac{i-i^{*}}{\lambda i^{*}-i^{*}} & \text { if } i^{*} \leqslant i<\lambda i^{*} \\ 0 & \text { if } i<i^{*}\end{cases}
$$

where $1 \leqslant \lambda<\infty$ and the variables are as defined above.

For a contract that protects against insufficient realisations of the underlying cumulative weather variable, the actuarially fair or pure premium rate is

$$
\begin{aligned}
\text { pure premium rate } & =E(\text { indemnity per dollar insured }) \\
& =\int_{0}^{\lambda i^{*}} h(i) \mathrm{d} i+\int_{\lambda i^{*}}^{i^{*}} \frac{i^{*}-i}{i^{*}-\lambda i^{*}} h(i) \mathrm{d} i
\end{aligned}
$$

where $h(i)$ is the probability density function of the underlying cumulative weather variable. The pure premium rate is the insurer's best estimate of the pure risk.

For a contract that protects against excessive realisations of the underlying cumulative weather variable, the actuarially fair premium rate is

$$
\begin{aligned}
\text { pure preminum rate } & =\text { E(indemnity per dollar insured }) \\
& =\int_{i^{*}}^{\lambda i^{*}} \frac{i-i^{*}}{\lambda i^{*}-i^{*}} h(i) \mathrm{d} i+\int_{\lambda i^{*}}^{\infty} h(i) \mathrm{d} i
\end{aligned}
$$

Risk loading costs

Ambiguity loads are also common when insuring against extreme weather risk events. Ambiguity loads protect against the possibility that the insurer incorrectly estimated the pure risk associated with the weather risk, possibly due to insufficient data. Changing trends, such as decreasing rainfall, also contribute to ambiguity and can significantly increase premium rates.

Catastrophic loads are also included in the cost of insuring against correlated risk. Catastrophic loads are based on the recognition that substantial losses may occur early in the life of the insurance programme before significant reserving funds accumulate.

\section{Administrative costs}

Delivery costs also add to the price of insurance. Sending sales agents to the countryside to visit individual farmers is expensive. This is particularly true in countries where individuals have little prior experience with any form of insurance. It may take multiple visits to convince a decision maker to purchase the insurance.

Other administrative costs such as office and staff overhead, product development, etc. must be accounted for and included in the premium. 


\section{Cost of ready access to capital}

The cost of ready access to capital adds more to the price of weather index insurance. Because weather index insurance underwrites correlated risk, insurers selling this product must rely on international reinsurance markets to assure solvency. Many insurers operating in lower income countries have little or no experience with reinsurance markets, which may, in some cases, increase the cost of capital or, when insurers are unable to obtain reinsurance, prevent the index insurance market from developing.

\section{Experience with index insurance programmes}

Some of the first weather index insurance pilots occurred in Mexico, India, Mongolia, Ethiopia, and Malawi in the early 2000s. Since then, at least 30 weather index insurance programmes have been piloted in lower and middle income countries. ${ }^{21}$ Despite the progress made with index insurance and the generally positive performance of welldesigned pilots, at this stage, there is insufficient empirical evidence to reach definitive conclusions about the efficacy of these programmes. The challenges of developing these markets in lower income countries are many, and in some cases (e.g. when weather data infrastructure is too underdeveloped, a suitable index cannot be found or the severe risk occurs too frequently), feasibility assessments indicate investments in other risk management strategies are likely to yield higher returns.

Experience with weather index insurance markets clearly shows that developing these markets involves high start-up costs. Not only do stakeholders have to design and market products, but also, education and capacity building among local insurance staff, delivery agents, government officials and consumers are needed. These capacity building investments likely contribute to broader financial service development; however, it is important to note that thus far, donors and/or governments have heavily supported the development of every weather index insurance markets. ${ }^{22}$ Still, interest in weather index insurance is increasing rapidly, and development efforts are expected to expand significantly.

\section{Climate change and insurance}

Having profiled weather index insurance, we now examine this product in the context of climate change adaptation. ${ }^{23}$ This examination begins by reviewing the ambiguity

${ }^{21}$ Barnett and Mahul (2007); Barnett et al. (2008); Ibarra and Syroka (2006).

22 Skees (2008) provides a more detailed overview and critical review of the challenges associated with providing weather index insurance in lower income countries.

${ }^{23}$ Climate change impacts are understood in the context of their effects on a weather distribution (e.g. changes in the mean, changes in the frequency or severity of extreme events). Because weather index insurance also relies on the weather distribution (to determine pure premium rates, as described above), lessons regarding the relationship between climate change impacts and insurance are particularly convenient to consider for weather index insurance. In contrast, the risk distributions of insurance products that base payments on expected loss distribution of the insured (e.g. for yield losses) are only partially correlated with weather distributions and additional extrapolations are needed to predict the ultimate effects of climate change impacts. 
surrounding climate change and the adaptation strategies available to farmers. Risk assessment is a critical aspect for prioritising adaptation investments as well as a first step to developing weather insurance markets. We also discuss the potential benefits of weather index insurance in the context of adaptation and the significant challenges that climate change presents to weather index insurance pricing. This review motivates our conclusions about the potential role of government and donors in providing assistance that will spur weather index insurance markets in lower income countries.

\section{Ambiguity and climate change}

Generally, climate describes the combination of weather patterns for a region over a long period of time (e.g. 30 years). Adapting to a changing climate is nothing new for farmers. However, recent scientific evidence about how anthropogenic contributions to greenhouse gases are leading to long-term consequences on a global level has increased the urgency for action. ${ }^{24}$

Models projecting the extent of climate change differ dramatically. Climate change is likely to affect different regions differently. In general, models predict temperatures will increase and rainfall will become erratic with some regions experiencing increasing intensity in rainfall. ${ }^{25}$ For example, Lobell et al. (2008) examine 20 global circulation models (GCMs) for 12 food-insecure regions (e.g. Southern Africa, South-East Asia) and find differing, sometimes conflicting results across models. All models agree that increasing average temperatures are likely; however, some projected less than $0.5^{\circ} \mathrm{C}$ warming while others projected $2.0^{\circ} \mathrm{C}$ warming when comparing the periods of 1980-2000 and 2020-2040. Rainfall projections were even less consistent with different models projecting positive and negative rainfall trends in each of the 12 regions.

A recent study by Optiz-Stapleton et al. ${ }^{26}$ illustrates the difficulty of creating regional projections of climate change impacts. The authors estimate a regional circulation model for rainfall in the Rohini Basin, a region in north-eastern India and southern Nepal. First, the authors choose a GCM and two climate change scenarios (A2 and B1). Climate change scenarios are researchers' educated guesses regarding future greenhouse gas emissions based on assumptions about future energy use and social and economic factors. The GCM used by Optiz-Stapleton et al., ${ }^{27}$ the Canadian Third Generation Coupled Climate Model, has a grid division of $3.75^{\circ} \times 3.75^{\circ}$ (latitude-longitude), which is equivalent to roughly $415 \mathrm{~km} \times 375 \mathrm{~km}$ for this region. For each weather variable the data are measured at the centre of the grid so each data point represents roughly $155,625 \mathrm{~km}^{2}$. Second, the authors integrate GCM projections with local characteristics such as topography and weather patterns. Optiz-Stapleton et $a l .{ }^{28}$ highlight three factors complicating this analysis: (1) limited and poor quality weather data, which is common in lower income countries; (2) atmospheric instability due to the proximity of the Himalayan Mountains; and (3) uncertainty associated with

\footnotetext{
${ }^{24}$ For example, Lobell et al. (2008); Bindoff et al. (2007); Carter et al. (2006); Stern (2006).

25 Lobell et al. (2008); Carter et al. (2006); Stern (2006).

${ }^{26}$ Optiz-Stapleton et al. (2008).

27 Ibid.

28 Ibid.
} 
larger circulation trends such as the South Asian Monsoon and El Niño Southern Oscillation (ENSO).

Optiz-Stapleton et al. $^{29}$ develop monthly rainfall projections, but report a "great deal of uncertainty" in these projections. They note predicting changes in extreme events is particularly difficult and that their model tends to under-predict extreme events. The authors conclude, "Without a better sense of potential climate change impacts at smaller geographic scales than $100-200 \mathrm{~km}$, it is difficult to begin planning and implementing adaptation or disaster risk reduction measures". 30

As Optiz-Stapleton et al. ${ }^{31}$ point out, rainfall and other weather patterns are largely affected by oceanic oscillations such as ENSO, which are determined by atmospheric pressure and sea surface temperatures. ${ }^{32}$ Scientists fear that documented increasing sea surface temperatures and changes in the atmospheric chemical composition attributed to climate change may disrupt global rainfall patterns in drastic ways due to changes in oceanic oscillations. GCMs project differing effects (including little or no effect) of climate change on oceanic oscillations; however, these models do not generally support a hypothesis that climate change will significantly disrupt the steady state conditions of oceanic oscillations during this century. ${ }^{33}$

In sum, despite general agreement among scientists that global warming and increasing intensity of rainfall are likely to continue occurring, the amount of change is largely uncertain. Perhaps even more important for our discussion, predicting climate changes on a regional level to a practicable degree is not currently possible. ${ }^{34}$

\section{Adapting to climate change}

Despite the inability of GCMs to predict climate change impacts at the local level, increasing weather risk due to climate change will result in increasing farm losses in some regions. When climate change may be increasing the risk exposure of those engaged in farming-related livelihoods, a major adaptation strategy is to change production behaviour. For example, farmers could adjust their crop portfolios or invest in irrigation or inputs that reduce the likelihood of losses. In extreme cases, farmers may decide that they can maximise expected utility by investing resources in areas other than farming. For instance, the farmer or a member of the family might pursue non-farm labour in a nearby town, city, or even another country as remittances have proven to be a significant source of income for the poor in many lower income countries. In sum, the solution for farmers facing climate change is to adapt - to change their investment portfolios in response to the new risk environment.

When farmers can do so, many will respond to expected farm losses because these tactics generate higher expected utility; however, this process can be difficult and

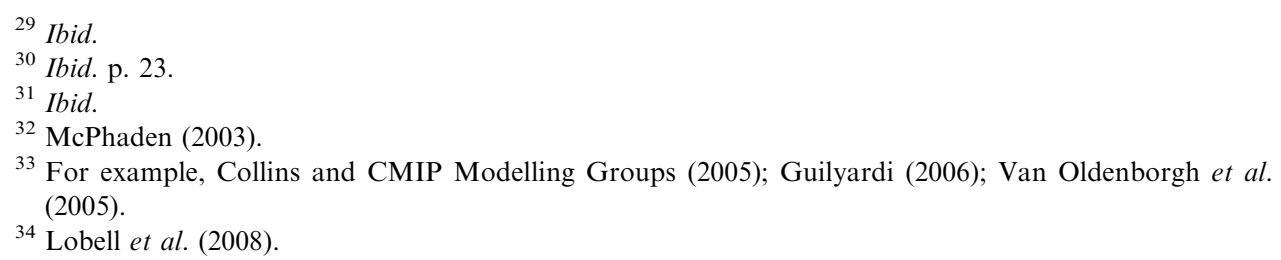


expensive. Some farmers, especially the poorest farmers, may not have the capacity to adapt without the assistance of governments and donors. Additionally, some lower income countries may not have the resources to aid adaptation without the assistance of higher income countries and donors.

\section{Risk assessment: understanding climate change in the local context}

Policy-makers recognising the gravity of potential climate change impacts and wanting to invest in adaptation face a conundrum: climate change is likely to have significant consequences yet the type and extent of these consequences remain particularly unclear at the regional level. To address this problem, a risk management approach that informs policy based on the likelihood and severity of a variety of outcomes can be highly valuable. ${ }^{35}$

The first step toward developing a risk management plan is to understand the risk and its effects on the specific local context. To do this, researchers conduct a risk assessment, which examines how a specific risk is affecting households, communities, businesses, governments, etc. ${ }^{36}$ This process also involves developing some knowledge about how the risk is being "paid for" in the society with current systems. Risk assessments examine the direct short- and long-term effects of the risk occurring; risk assessments also examine potential indirect effects of the risk such as lost business opportunities and a slowed economy. For example, a risk assessment may reveal that households avoid farming certain high-value crops because of the risk of concern, communal reciprocity systems collapses during a catastrophic event, banks fail to provide loans to households exposed to the weather risk, input suppliers and agricultural processors are unwilling to enter a region because yield variability is too high, and governments spend a great deal on disaster assistance for the same region which is devastated every few years. All of these factors help with assessing the social cost of the risk in the current environment.

Risk assessments may also be used to examine how climate change would likely affect stakeholders. Starting from the findings of the more generic risk assessment, researchers can take information about vulnerable populations, production strategies, and natural resources, and estimate the likely effect of specific climate change impacts temperature increases, rainfall changes, increasing sea levels, etc. ${ }^{37}$ For example, Lobell et al. ${ }^{38}$ use crop models and climate projections to estimate that wheat and maize in Southern Africa, two crops important to food security, are extremely vulnerable to temperature and rainfall changes.

\footnotetext{
${ }^{35}$ IPCC (2007); Yohe (2006).

${ }^{36}$ For our purposes we consider assessing a catastrophic risk because some of these are likely to increase and are of particular concern for vulnerable populations.

${ }^{37}$ In some cases, climate change impacts may most significantly affect a population that was not considered vulnerable before the climate change impact occurred (e.g. industrialised farms, coastal urban centres), but in these cases as well, better-off households should be able to adapt more easily than poorer households.

${ }^{38}$ Lobell et al. (2008).
} 
Understanding current risks and identifying vulnerable populations can be valuable for local decision makers and is likely to contribute to economic development through improved risk management. This form of risk assessment should be the starting point for policy frameworks for climate change adaptation. ${ }^{39}$ Unfortunately, these risk assessments are seldom performed in lower income countries.

\section{Publicly supported adaptation investments}

Because adapting livelihood strategies to climate change - whether by changing farming systems or changing occupations - can be very difficult and costly for farm households, opportunities abound for governments and donors to facilitate this process. Several types of interventions are noteworthy given the potential adaptations farmers must make.

Improved seed varieties may be very important for future food insecure regions. Development of seed varieties that are suitable for the emerging climate conditions can greatly benefit farmers who have sunk costs and specialised skills in a particular type of farming. Many times this requires localised research to tailor seed varieties to local soils, management and climate.

Investments in infrastructure can also be quite important for farmer adaptation. Irrigation and the development of appropriate water markets can greatly benefit farmers facing rainfall declines; however, decreasing rainfall could reduce available water supplies limiting opportunities for irrigation in many regions. Improvements in roads can increase farmers' access to distant markets for new agricultural commodities. Similarly, road improvements can increase access to labour markets, improving opportunities for transitions to new livelihoods.

Farmer training can also be important. Extension services that educate farmers in new farm management systems such as switching crops or improving water management can facilitate farmer adaptation. Also, because some rural families have specialised in agriculture for many generations, programmes that provide farmers with new technical skills may be particularly appropriate when climate change is so severe that farmers must transition to new livelihoods.

\section{Potential benefits of weather index insurance in regions affected by climate change}

Multilateral institutions on climate change have highlighted the importance of insurance in the context of adaptation and many are pointing to weather index insurance because of the positive experiences of weather index insurance pilots in lower income countries. Unlike the examples of adaptation investments cited in the previous section, purchasing insurance is not truly a means of adaptation because it does not address the underlying problem - that climate change is causing traditional agricultural production to become riskier. ${ }^{40}$ Still, researchers make several arguments

\footnotetext{
${ }^{39}$ See Adger et al. (2007).

${ }^{40}$ Mileti (1999).
} 
for why weather index insurance could be important in the context of adapting to climate change.

First, weather index insurance pilots have been designed to protect households from catastrophic weather events. Given the likely increase of extreme events associated with climate change impacts in some regions, weather index insurance could play a key role in protecting vulnerable households. In this fashion, weather index insurance increases the resilience, including the adaptive capacity, of the insured.

Second, insurance markets are likely to motivate households to adapt through price signals. Insurance has a long history of using price signals to reduce vulnerability. For many risks in lower income countries, insurance provides a first-time estimate of the monetary cost of the risk being insured. Many households may be unaware of the monetary cost of their production risk - many households have likely never been exposed to this way of thinking. ${ }^{41}$ The price of weather index insurance may allow households to improve their decision-making process regarding whether they need to adapt, and if they do decide to change their behaviours, how and to what extent they must change.

Third, insurance provides cash at opportune times for the insured to adapt. After a catastrophic event occurs, households must decide whether they will continue in their previous livelihood strategies, often requiring households to restock damaged assets, or if they will change livelihood strategies, often requiring capital investments. A major difficulty for lower income populations is that they lack the financial means to adapt. ${ }^{42}$ Cash payments from an insurer improve opportunities for farmers to make the capital investments needed to adapt or to maintain their current production strategies.

Fourth, weather index insurance can encourage adaptation by being bundled with new technologies. Bundling weather index insurance with drought-resistant seed, for example, may increase access to both the seed and insurance for households. A weather index insurance programme in Malawi bundled weather index insurance with loans for high-yield groundnut varieties. Farmers were unable to gain access to loans for these high-yield varieties before the insurance product was introduced because lenders considered the risk too great. ${ }^{43}$

While several arguments are thus advanced about the value of weather index insurance for regions experiencing climate change, climate change creates problems for pricing weather index insurance.

${ }^{41}$ This benefit of weather index insurance is based on the assumption that the price of the insurance accurately reflects the best estimates of the underlying risk, an assumption that should not be overlooked. While this assumption is most plausible in competitive markets, access to competitive markets for insurance is unlikely for many rural households in lower income countries, especially since weather index insurance is such a novel product. As we discuss below, climate change creates additional problems for pricing weather index insurance that challenge the notion that insurance prices act as an important signal to households.

${ }^{42}$ United Nations Framework Convention on Climate Change (2007).

${ }^{43}$ Hess and Syroka (2005). 
414

\section{Difficulties for developing weather index insurance due to climate change}

The primary difficulty of climate change impacts for weather index insurance pertains to the uncertainty associated with the impact of future climate trends in the region. Not only does this uncertainty increase the ambiguity and catastrophe loads insurers must charge, but where severe changes in the distribution of the underlying weather risk occur, weather index insurance programmes may be unsustainable. Given the high costs of developing a weather index insurance programme, this business risk is likely to reduce the willingness of insurers to develop weather index insurance markets in some regions.

Increasing weather risk resulting from climate change affects the price of insurance in two ways. First, ambiguity and catastrophe loads increase because uncertainty associated with future climate change impacts leads insurers to plan for the worst likely scenario when establishing these loads. Second, increasing weather risk changes the pure risk. In terms of the probability density function of a specific weather variable, changes in weather risk occur in two important ways: (1) shifts in the central tendency of the probability distribution of a weather event and/or (2) changes in the variance of the distribution.

Shifts in the central tendency can dramatically increase the cost of insurance. To illustrate, we consider the pure risk associated with a hypothetical rainfall insurance contract that could emerge given three different time periods between 1900 and 2007 using rainfall data from the Sahel. The Sahel, a region in Africa south of the Sahara, has a dynamic climate - experiencing multi-decadal trends in rainfall due to oceanic oscillations. ${ }^{44}$

Figure 1 shows rainfall in the Sahel during the summer growing season (June, July and August) from 1900 to $2006 .^{45}$ The black line is the annual data; the grey line running through the centre of the black line is a 10-year moving average. The boxes around the data in Figure 1 identify the time periods of data for the three probability density functions.

In this illustration, we do not intend to communicate that trends in Sahel rainfall are a result of climate change due to greenhouse gas emissions; rather, our purpose is to illustrate some core principles using procedures that an insurance underwriter might use to assess data with changing rainfall patterns.

We assume that an insurer enters into this environment at three different points in time and has only a limited amount of data to develop an index insurance against deficit rainfall. The first time period is from the vantage point of 1962. Looking back, the insurer has data from 1900 to 1961. The second time period is from the vantage point of 1990 assuming that the insurer only has data from 1962 to 1989. Finally, the last time period is 2007, assuming that the insurer enters in 2007 and only has data from 1990 to 2006.

Insurers would adjust these data for trend. First, insurers make a forecast of the central tendency for the next insurance period using the trend line. Second, insurers

\footnotetext{
${ }^{44}$ Desanker and Magadza (2001); Hulme et al. (2001).

${ }^{45}$ These data are averaged across weather stations across the Sahel with the majority of stations concentrated in the western-most region.
} 


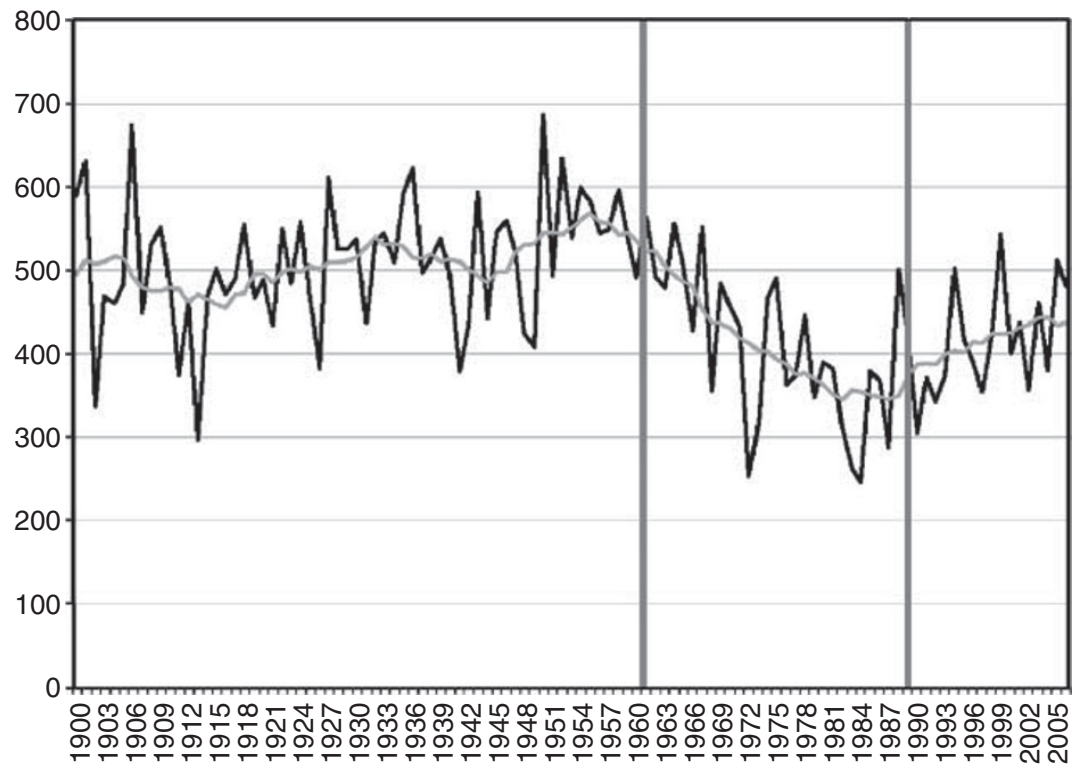

Figure 1. Sahel Rainfall in mm, 1900-2006. Source: Authors, based on data provided by International Research Institute for Climate and Society, Columbia University.

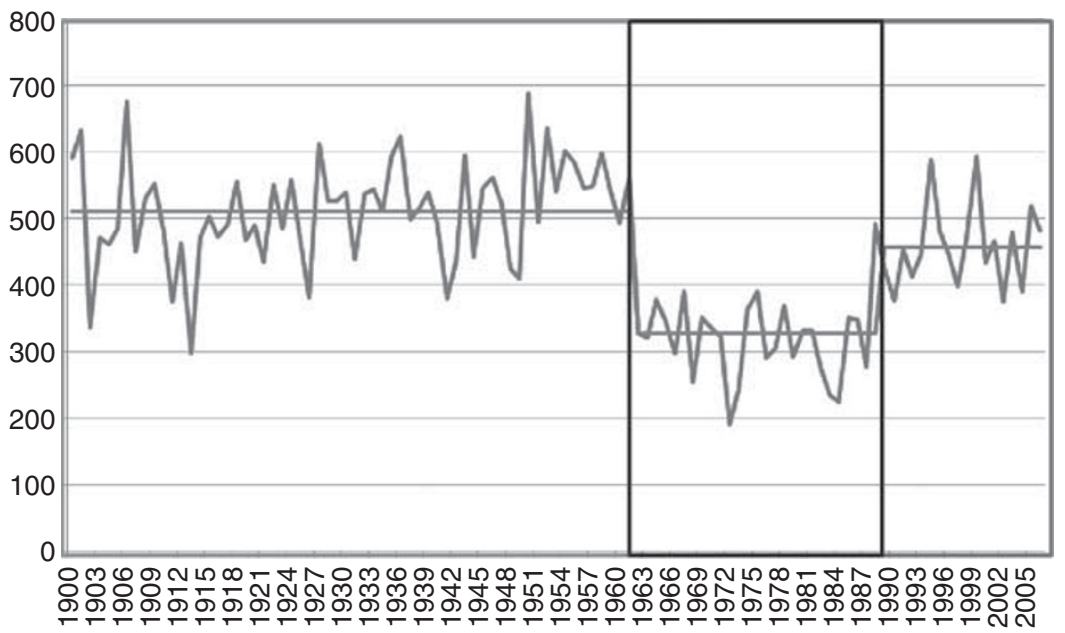

Figure 2. Weather data adjusted for trends from vantage points, 1962, 1990, and 2007. Source: Authors, based on data provided by International Research Institute for Climate and Society, Columbia University.

centre the rainfall observations on the forecasted central tendency. Given the different vantage points and available data as described above, the total data set after the independent trend adjustments is represented in Figure 2. 
Suppose that our hypothetical insurer decided to offer weather index insurance against drought to wheat farmers at these three different points in time $(1962,1990$, and 2007). Also, suppose that, based on agronomic knowledge of rainfall needs, the contract threshold is set at $425 \mathrm{~mm}$ of rainfall, indemnities increase uniformly for every $\mathrm{mm}$ of rainfall less than $425 \mathrm{~mm}$, and the contract limit is $200 \mathrm{~mm}$ where payout is 100 per cent of the sum insured because total crop failure is assumed. Given the details of this hypothetical contract, insurers would look at the probability density function for rainfall to determine the pure risk. For the sake of simplicity, we assume a normal distribution for this illustration and obtain probability distributions for two of the vantage points, 1962 and 1990 (see Figure 3).

Figure 3 provides the estimated probability density functions, central tendencies, variances, and pure risk levels for the insurance contract.

Based on the $425 \mathrm{~mm}$ threshold, the shaded area identifies the area under each probability distribution associated with an insurance pay-out, which represents the pure risk. The forecasted central tendency developed for 1962 is $510 \mathrm{~mm}$, resulting in a pure risk of 2 per cent for this insurance contract, a low and almost surely affordable level of pure risk. In contrast, the forecasted central tendency from 1990 is $328 \mathrm{~mm}$, which is below the threshold of $425 \mathrm{~mm}$. The pure risk is very high -44 per cent. Insurance could not be designed for this scenario and would be an inefficient solution. Obviously, farmers would be unable to pay for insurance products underwriting this level of risk.

This example illustrates the complication of using historical data to predict future trends in the presence of changing risk. In Figure 3, an insurer in 1962 would have priced rainfall insurance based on the solid-line distribution, but the dotted-line distribution reflects expectations for rainfall in 1990 based on the data from 1962 to 1989. Any insurer entering the market in 1962 would have experienced significant losses because of the changing climate conditions. The insurer would have continually adjusted prices to account for its loss experience; however, because these two time periods are so different, it is unlikely the insurer could adjust prices quickly enough to remain solvent. During this time, farmers almost certainly perceived the changes in the central tendency, and the price increases and perhaps failure of the hypothetical insurer would have contributed to a message likely already developing in the minds of these farmers - "maybe you should not be trying to grow wheat".

\section{Conclusions and extensions of the Sahel example}

In this illustration, we see that shifts in the central tendency can have dramatic effects on the pure risk and, thus, the price of insurance. Insurance costs are very sensitive to shifts in the central tendency, primarily because the central tendency describes the set of conditions that are most likely to occur. Additionally, the Sahel example illustrates the difficulty that insurers may be unable to identify whether an insurance programme is sustainable in the long term due to potential changes in the climate.

The Sahel is a somewhat unique example. Its dramatic multi-decadal rainfall cycles and relatively constant variance make it a useful case for this illustration; however, the Sahel experience is not consistent with future climate change scenarios. The dynamic 


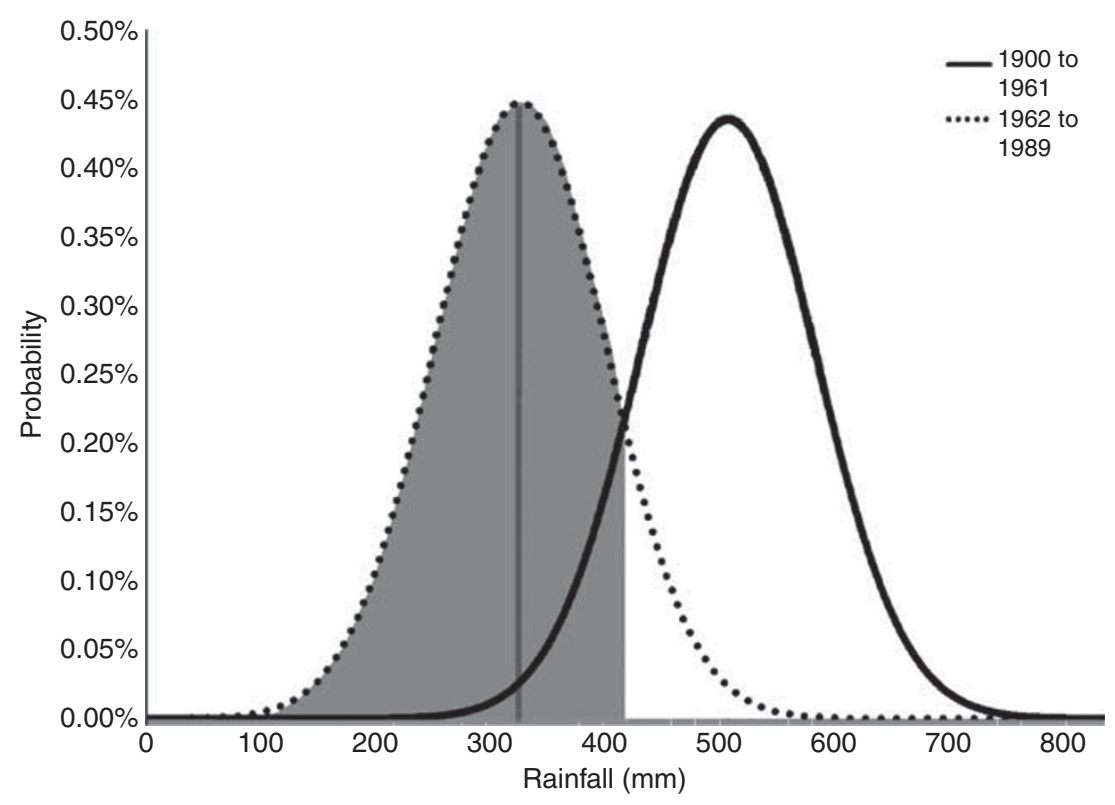

\begin{tabular}{lcccc}
\hline Vantage Point & Data & Central Tendency & Variance & Pure Risk \\
\hline 1962 & $1900-1961$ & 510 & 77 & $2 \%$ \\
\hline 1990 & $1962-1989$ & 328 & 76 & $44 \%$
\end{tabular}

Figure 3. Comparing rainfall distributions and payouts, created using the vantage points of 1962 and 1990. Source: Authors, based on data provided by International Research Institute for Climate and Society, Columbia University.

climate of the Sahel seems to be the result of a complex interaction of natural and human factors - oceanic oscillations decrease rainfall which leads farmers to overextend natural resources, increasing desertification. ${ }^{46}$ Unlike the Sahel example, GCMs projecting even the worst case scenarios do not tend to find that climate change will result in a 35 per cent decline over three decades in the central tendency of important weather variables, which occurred in the Sahel. For example in the most severely affected regions, GCMs tend to project up to a 20 per cent decrease in average precipitation by 2080-2099 relative to $1980-1999 .^{47}$

Rather than significant shifts in the central tendency, the most dramatic effects of climate change on weather risk distributions seem likely to occur in the form of

${ }^{46}$ Desanker and Magadza (2001); Hulme et al. (2001).

${ }^{47}$ Meehl et al. (2007). Even a small change in the central tendency of some variables can have significant implications due to interactive effects. For example, relatively minor increases in temperature can significantly affect plant growth and water requirements. Such interactions could potentially require a change in the pay-out structure of an insurance product. 
increasing extreme events (e.g. increasing variance in the probability distribution). Identifying changes in extreme events is complex and requires more data than changes in the central tendency; however, ${ }^{48}$ report increasing rainfall variability is likely to occur in some regions as a result of climate change. Insurance is designed to reduce variability, which makes it a potentially effective mechanism for extreme weather risks that are increasing in frequency and/or severity. The price of insurance must increase if insured extreme events are increasing; however, trends in extreme events are likely to have a smaller effect on the price of insurance than trends in the central tendency. In the Sahel example, the estimated pure risk in 1962 was 2 per cent. A 35 per cent decrease in the central tendency resulted in an estimated pure risk of 44 per cent in 1990 (an increase of over 2,100 per cent of the pure risk), whereas a 35 per cent increase in the variance in 1962 would result in an estimated pure risk of 5 per cent (an increase of 150 per cent). Because changes in extreme events are more difficult to identify, insurers are particularly likely to increase the ambiguity and catastrophe loads for these events.

As we noted in the weather index insurance section, households exhibit a cognitive failure in that they underestimate the likelihood of catastrophic events; therefore, insurance products that price this risk based on historical data and the best scientific projections of changes in the risk may be particularly important. This price signal can help farmers see the cost of risk more clearly and pushes them to make difficult choices farmers can continue in the same farming practices as production risks increase or they can adapt to the new climate conditions. ${ }^{49}$ However, anticipating how farmers will interpret these price signals is complicated by cognitive failure, which may instead result in farmers interpreting high insurance prices as insurers overpricing the risk. It should also be recognised that in many cases, the opportunity cost of purchasing insurance is so high or household adaptive capacity is so low that price signals are insufficient to elicit change in households.

\section{Policy recommendations}

Difficult choices are ahead for governments, donors and individual decision-makers as they struggle with how to adapt to climate change. Care is needed to ensure that interventions for vulnerable populations do not work at cross purposes with adaptation goals. For example regarding insurance and climate change, direct premium subsidies from the government or donors may actually impede household adaptation to climate change (discussed in more detail below). ${ }^{50}$ This is clearly not the intent of Article 4.8 of the UNFCCC.

Instead, we encourage government and donor support of risk assessments. Countryspecific comprehensive risk assessments are a necessary first step if informed decisions are to be made regarding the allocation of scarce climate change adaptation resources.

\footnotetext{
${ }^{48}$ Carter et al. (2006).

49 Mileti (1999).

${ }^{50}$ While our focus is on weather index insurance, this discussion is relevant to any insurance market that insures against losses created by extreme weather events.
} 
Risk assessments allow decision-makers to better understand the historical frequency and magnitude of loss for various extreme weather events, how extreme weather events affect different stakeholders in the country, how the country's current institutional structure affects incentives to manage risk, and how changes in the historical frequency and magnitude of loss would likely affect stakeholders.

In some cases, risk assessments will suggest that weather insurance markets can play a role in climate change adaptation. Since agriculture is a dominant activity for so many in lower income countries and many relevant adaptation and development investments are needed, it is quite likely that risk assessments will also point to other adaptation strategies (e.g. irrigation, modified cropping systems, different crop mixes) that should be considered alongside (or perhaps even in place of) weather insurance.

Weather index insurance will work best in regions where catastrophic weather risks are creating significant welfare and economic losses, financial risk management is likely more effective than physical mitigation, and climate change seems to be resulting in increased weather risk variability. When risk assessments suggest a role for weather insurance markets in climate change adaptation, it would be naive to assume that these markets will emerge in lower income countries without some form of assistance. The challenge is to provide the necessary assistance while avoiding the unintended consequence of impeding other adaptation strategies.

\section{Start-up costs}

Governments or donors can also finance the start-up costs required to develop functioning weather insurance markets within lower income countries. Beyond the first step of financing the comprehensive risk assessment described above, governments or donors can finance activities such as disseminating the risk assessment findings to local stakeholders, improving access to weather data, enhancing weather data infrastructure, improving physical mitigation infrastructure, creating an enabling legal and regulatory environment for weather insurance markets, and educating household decision-makers about the use of insurance and other financial services. These efforts should stimulate the development of weather insurance markets without distorting insurance prices and creating disincentives for insured individuals to adopt other climate change adaptation strategies. Furthermore, these activities would generate public benefits that extend well beyond addressing the local effects of climate change through a more complete understanding of effective strategies to manage risks in that region.

\section{Difficulties with premium subsidies}

Some have suggested that when climate change increases the cost of weather index insurance beyond the means of farmers, the government should intervene and pay a portion of farmer premiums so that they can continue farming. While these propositions are well-intended, policy-makers should maintain caution in pursuing this strategy. Premium subsidies can distort price signals and create disincentives for farmers to adapt to climate change - thereby actually increasing the vulnerability of farm households to the risks associated with climate change. 
420

Subsidised insurance can cause economic inefficiencies by encouraging farmers to invest in production strategies that are not suited for local market or environmental conditions. For example, in the United States, subsidised insurance has motivated farmers to produce water-dependent crops in areas that suffer frequent droughts. ${ }^{51}$ Additionally, U.S. policies regarding insurance subsidies have contributed to increasing losses and increasing government costs over time. ${ }^{52}$ When the government pays a fixed percentage of total farmer premiums, it tends to mostly benefit the riskiest farmers, those who have the highest insurance premiums. This can encourage farmers to take more risks by planting on more marginal lands because if farmers lose crops, insurance will cover the losses and if farmers have a good year, they retain the profits. These experiences illustrate the maxim: if people are paid to take more risks, they will.

Premium subsidies may be particularly prone to creating these undesired consequences when climate change results in shifts to the central tendency. To illustrate, a study using U.S. farmers found participants were able to accurately predict the central tendency in their farm yields without engaging in any handwritten calculations. Farmers experiencing trends in their yields even adjusted their estimate of the central tendency for trend without being prompted. ${ }^{53}$ Because individuals are implicitly aware of such trends, the potential for premium subsidies to create perverse incentives seems more likely when climate change impacts affect the central tendency of important weather risks. To the point, when insuring against catastrophic weather events, any subsidies should be carefully constructed to reduce the potential for perverse behavioural incentives.

\section{Catastrophic risk layer}

A carefully structured risk-layering approach, where subsidies are used only to finance the most extreme layer of risk, can reduce the likelihood that subsidies will distort incentives to adapt. ${ }^{54}$ This approach will work best if the primary impact of climate change is increased variability in weather and not significant changes to the central tendency of important weather variables. Increased variability implies an increased likelihood of catastrophic weather events, yet studies have shown that: (1) individuals typically do not know the likelihood, or potential magnitude of catastrophic weather events; (2) they are unable or unwilling to consider the potential impacts of lowprobability catastrophic events; and (3) they tend to forget about past extreme events. ${ }^{55}$ To account for this cognitive failure, governments or donors could finance the most extreme layer of risk - that layer for which individuals fail to plan. ${ }^{56}$ Because individuals generally fail to take such low-frequency, high-severity events into

${ }^{51}$ Skees (2001); Wu (1999).

${ }^{52}$ Goodwin et al. (2004); Skees (2001).

${ }^{53}$ Buzby et al. (1994).

${ }^{54}$ Of course, any government intervention that reduces the cost of insurance can be seen as affecting the price signal. In this context, policy-makers would do well to recognise the trade-off between protecting vulnerable populations and reducing their incentives to adapt.

${ }^{55}$ Buzby et al. (1994); Rossi et al. (1982); Kunreuther and Slovic (1978); Kunreuther (1976).

${ }^{56}$ Skees and Barnett (1999). 
consideration, insurance subsidies that are limited to a catastrophic layer of risk are less likely to affect other adaptation decisions.

Government or donor efforts to finance the most extreme layer of risk can also "crowd in" private-sector weather insurance markets for risk layers that reflect more frequent but less extreme weather events. Government or donor provision of catastrophic coverage should reduce the cost of complementary insurance products for three reasons. First, the pure risk for a complementary private insurance product is lower since the product does not have to cover the catastrophic layer of risk. Second, the need for catastrophic loading is greatly reduced. Third, the ambiguity load can also be reduced because the ambiguity is greatest for low-probability, high-consequence, catastrophic events.

\section{Conclusion}

Similar to economic development agendas, designing effective climate change adaptation policies is complicated by organisation and information problems: those planning the allocation of needed resources are at the national and (most often) international level while implementation to benefit vulnerable households and communities occurs in a local context. Thus, national and multilateral institutions must strive to benefit from economies of scale for research developments, overarching frameworks, organising resources and financing while developing appropriate solutions that are relevant to the nuanced problems of stakeholders in local communities.

Weather index insurance is but one tool among many that can be used to address the impacts of climate change. Governments and donors should carefully consider the opportunity cost of other foregone adaptation efforts before committing available climate change adaptation funds for weather index insurance development. When risk assessments suggest that weather insurance is an appropriate adaptation tool, government and donor assistance should focus on funding the start-up costs of developing weather insurance markets and the catastrophic layer of risk. By focusing on these activities, governments and donors can reduce the potential for creating disincentives that impede the adoption of other climate change adaptation strategies.

\section{References}

Adger, W.N., Agrawala, S., Mirza, M.M.Q., Conde, C., O’Brien, K., Pulhin, J., Pulwarty, R., Smit, B. and Takahashi, K. (2007) 'Assessment of adaptation practices, options, constraints and capacity', in M.L. Parry, O.F. Canziani, J.P. Palutikof, P.J. van der Linden and C.E. Hanson (eds) Climate Change 2007: Impacts, Adaptation and Vulnerability. Contribution of Working Group II to the Fourth Assessment Report of the Intergovernmental Panel on Climate Change, Cambridge, UK: Cambridge University Press, pp. 717-743.

Barnett, B.J. and Mahul, O. (2007) 'Weather index insurance for agriculture and rural areas in lower-income countries', American Journal of Agricultural Economics 89: 1241-1247.

Barnett, B.J., Barrett, C.B. and Skees, J.R. (2008) 'Poverty traps and index-based risk transfer products', World Development 36: 1766-1785.

Besley, T. (1995) 'Nonmarket institutions for credit and risk sharing in low income countries', Journal of Economic Perspectives 9(3): 115-127. 
Bindoff, N.L., Willebrand, J., Artale, V., Cazenave, A., Gregory, J., Gulev, S., Hanawa, K., Le Quéré, C., Levitus, S., Nojiri, Y., Shum, C.K., Talley, L.D. and Unnikrishnan, A. (2007) 'Observations: oceanic climate change and sea level', in S. Solomon, D. Qin, M. Manning, Z. Chen, M. Marquis, K. B. Averyt, M. Tignor and H. L. Miller (eds) Climate Change 2007: The Physical Science Basis, Working Group I Contribution to the Fourth Assessment Report of the Intergovernmental Panel on Climate Change, Cambridge, UK: Cambridge University Press, pp. 385-432.

Buzby, J.C., Kenkel, P.L., Skees, J.R., Pease, J.W. and Benson, F.J. (1994) 'A comparison of subjective and historical yield distributions with implications for multiple peril crop insurance', Agricultural Finance Review 54: 15-23.

Carter, T.R., Jones, R.N., Lu, X., Bhadwal, S., Conde, C., Mearns, L.O., O’Neill, B.C., Rounsevell, M.D.A. and Zurek, M.B. (2007) 'New assessment methods and the characterisation of future conditions', in M.L. Parry, O.F. Canziani, J.P. Palutikof, P.J. van der Linden and C.E. Hanson (eds) Climate Change 2007: Impacts, Adaptation, and Vulnerability, Working Group II Contribution to the Fourth Assessment Report of the Intergovernmental Panel on Climate Change, Cambridge, UK: Cambridge University Press, pp. 133-172.

Carter, M.R., Little, P.D., Mogues, T. and Negatu, W. (2005) The long-term impacts of short-term shocks: Poverty traps and environmental disasters in Ethiopia and Honduras, Basis Brief 28, Department of Agricultural and Applied Economics, University of Wisconsin, Madison, WI.

Carter, M.R., Little, P.D., Mogues, T. and Negatu, W. (2006) Shocks, sensitivity and resilience: Tracking the economic impacts of environmental disaster on assets in Ethiopia and Honduras, Discussion Paper No. 32, International Food Policy Research Institute, Washington, DC.

Collins, M. and CMIP Modelling Groups (2005) 'El Niño- or La Niña-like climate change?' Climate Dynamics 24: 89-104.

Corbera, E., Conway, D., Goulden, M. and Vincent, K. (2006) Climate change in Africa: Linking science and policy for adaptation, Royal Society Workshop Report G00022, Norwich and London: The Tyndall Centre and International Institute for Environment and Development.

de Janvry, A., Fafchamps, M. and Sadoulet, E. (1991) 'Peasant household behaviour with missing markets: Some paradoxes explained', The Economic Journal 101: 1400-1417.

Dercon, S. (1998) 'Wealth, risk, and activity choice: Cattle in western Tanzania', Journal of Development Economics 55(1): 1-42.

Desanker, P.V. and Magadza, C. (2001) 'Africa', in J.J. McCarthy, O.F. Canziani, N.A. Leary, D.J. Dokken and K.S. White (eds) Climate Change 2001: Impacts, Adaptation and Vulnerability, Working Group II Contribution to the Third Assessment Report of the Intergovernmental Panel on Climate Change, Cambridge, UK: Cambridge University Press, pp. 487-532.

Goodwin, B.K., Vandeveer, M. and Deal, J. (2004) 'An empirical analysis of acreage distortions and participation in the federal crop insurance programme', American Journal of Agricultural Economics 86: 1058-1077.

Guilyardi, E. (2006) 'El Niño-mean state-seasonal cycle in a multi-model ensemble', Climate Dynamics 26: 329-348.

Hazell, P.B.R. (1992) 'The appropriate role of agricultural insurance in lower income countries', Journal of International Development 4: 567-581.

Hazell, P.B.R. and Skees, J.R. (2006) 'Insuring against bad weather: Recent thinking', in R. Radhakrishna, S.K. Rao, S. Mahendra Dev and K. Subbarao (eds) India in a Globalising World: Some Aspects of Macroeconomy, Agriculture, and Poverty, New Delhi: Academic Foundation.

Hess, U. (2003) Innovative financial services for rural India: Monsoon-indexed lending and insurance for smallholders, working paper no. 9, Agriculture and Rural Development Department, The World Bank, Washington, DC.

Hess, U. and Syroka, J. (2005) Weather-based insurance in southern Africa: The case of Malawi, discussion paper 13, Agriculture and Rural Development Department, The World Bank, Washington, DC.

Hulme, M., Doherty, R., Ngara, T., New, M. and Lister, D. (2001) 'African climate change: 1900-2100', Climate Research 17: 145-168.

Ibarra, H. and Syroka, J. (2006) 'Case studies for agricultural weather risk management', in E. Castiglione (ed) Risk Management in Agriculture for Natural Hazards, Rome: ISMEA.

IPCC (2007) Climate Change 2007: Synthesis Report, Contribution of Working Groups I, II and III to the Fourth Assessment Report of the Intergovernmental Panel on Climate Change (Core Writing Team, Pachauri, R.K and Reisinger, A. (eds)) Geneva, Switzerland: IPCC, pp. 104. 
Kunreuther, H. (1976) 'Limited knowledge and insurance protection', Public Policy 29: 227-261.

Kunreuther, H. and Slovic, P. (1978) 'Economics, psychology, and protective behaviour', American Economic Review 68: 64-69.

Linnerooth-Bayer, J., Amendola, A., Okada, N. and Shi, P. (2007) 'Disaster risk management: Pro-active financing to reduce vulnerability', Environmental Hazards 7: 1-6.

Lobell, D.B., Marshall, B.B., Tebaldi, C., Mastrandrea, M.D., Falcon, W.P. and Naylor, R.L. (2008) 'Prioritising climate change adaptation needs for food security in 2030', Science 319: 607-610.

Martin, S.W., Barnett, B.J. and Coble, K.H. (2001) 'Developing and pricing precipitation insurance', Journal of Agricultural and Resource Economics 26: 261-274.

McPeak, J.G. and Barrett, C.B. (2001) 'Differential risk exposure and stochastic poverty traps among East African pastoralists', American Journal of Agricultural Economics 83: 674-679.

McPhaden, M.J. (2003) 'El Niño and La Niña: Causes and global consequences', in M.C. MacCracken and J.S. Perry (eds) Encyclopedia of Global Environmental Change, Volume 1, The Earth System: Physical and Chemical Dimensions of Global Environmental Change, Hoboken, NJ: John Wiley and Sons, pp. 353-370.

Meehl, G.A., Stocker, T.F., Collins, W.D., Friedlingstein, P., Gaye, A.T., Gregory, J.M., Kitoh, A., Knutti, R., Murphy, J.M., Noda, A., Raper, S.C.B., Watterson, I.G., Weaver, A.J. and Zhao, Z.-C. (2007) '2007: Global Climate Projections', in S. Solomon, D. Qin, M. Manning, Z. Chen, M. Marquis, K.B. Averyt, M. Tignor and H.L. Miller (eds) Climate Change 2007: The Physical Science Basis. Contribution of Working Group I to the Fourth Assessment Report of the Intergovernmental Panel on Climate Change, Cambridge, UK and New York, NY, USA: Cambridge University Press.

Mileti, D.S. (1999) Disaster by Design: A Reassessment of Natural Hazards in the United States, Washington, DC: Joseph Henry Press.

Morton, J.F. (2007) 'The impact of climate change on smallholder and subsistence agriculture', Proceedings of the National Academies of Sciences 104: 19680-19685.

Nicholls, R.J., Wong, P.P., Burkett, V.R., Codignotto, J.O., Hay, J.E., McLean, R.F., Ragoonaden, S. and Woodroffe, C.D. (2007) 'Coastal systems and low-lying areas', in M.L. Parry, O.F. Canziani, J.P. Palutikof, P.J. van der Linden and C.E. Hanson (eds) Climate Change 2007: Impacts, Adaptation and Vulnerability, Contribution of Working Group II to the Fourth Assessment Report of the Intergovernmental Panel on Climate Change, Cambridge, UK: Cambridge University Press, pp. 315-356.

The Risk to Resilience Study TeamOptiz-Stapleton, S., and Gangopadhyay, S. (2008) Downscaling: Potential climate change impacts in the Rohini Basin, Nepal and India, From Risk to Resilience Working Paper 3, ISET, ISET-Nepal, and ProVention, Kathmandu, Nepal.

Rosenzweig, M.R. and Binswanger, H.P. (1993) 'Wealth, weather risk, and the composition and profitability of agricultural investments', Economic Journal 103: 56-78.

Rosenzweig, M.R. and Wolpin, K.I. (1993) 'Credit market constraints, consumption smoothing, and the accumulation of durable production assets in low-income countries: Investments in bullocks in India', Journal of Political Economy 101: 223-244.

Rossi, P., Wright, J. and Weber-Burdin, E. (1982) Natural Hazards and Public Choice: The State and Local Politics of Hazard Mitigation., New York, NY: Academic Press.

Sachs, J.D. and Arthur, J.W. (2005) 'The millennium project: A plan for meeting the millennium development goals', Lancet 365: 347-353.

Skees, J.R. (2001) 'The bad harvest: More crop insurance reform: A good idea gone awry', Regulation: The CATO Review of Business and Government 24: 16-21.

Skees, J.R. (2008) 'Challenges for use of index-based weather insurance in lower income countries', Agricultural Finance Review 68: 197-217.

Skees, J.R. and Barnett, B.J. (1999) 'Conceptual and practical considerations for sharing catastrophic/ systemic risks', Review of Agricultural Economics 21: 424-441.

Skees, J.R. and Barnett, B.J. (2006) 'Enhancing microfinance using index-based risk transfer products', Agricultural Finance Review 66: 235-250.

Skees, J.R. and Collier, B. (2008) The potential of weather index insurance for spurring a green revolution in Africa, paper presented to the Alliance for a Green Revolution in Africa (AGRA) workshop, Policies for Achieving Africa's Green Revolution: Agenda for Action, Nairobi, Kenya.

Stern, N. (2006) Stern Review Report on the Economics of Climate Change, Cambridge: Cambridge University Press. 
United Nations Framework Convention on Climate Change. (2007) Climate Change: Impacts, Vulnerabilities and Adaptation in Developing Countries, Report issued by Climate Change Secretariat (UNFCCC), Bonn, Germany.

van Oldenborgh, G.J., Phillip, S.Y. and Collins, M. (2005) 'El Niño in a changing climate: A multi-model study', Ocean Science 1: 81-95.

Vedenov, D.V. and Barnett, B.J. (2004) 'Efficiency of weather derivatives as primary crop insurance instruments', Journal of Agricultural and Resource Economics 29: 387-403.

World Bank (2008) World Development Report 2008: Agriculture for Development, Washington, DC.

Wu, J. (1999) 'Crop insurance, acreage decision, and nonpoint-source pollution', American Journal of Agricultural Economics 81: 305-320.

Yohe, G.W. (2006) 'Representing dynamic uncertainty in climate policy deliberations', Ambio 35: 89-91.

\section{About the Authors}

Benjamin Collier is a research analyst for GlobalAgRisk and doctoral student in the Department of Agricultural Economics, University of Kentucky. Collier wrote a World Bank Institute course on weather index insurance for agriculture and developed reports and presentations for Asian Development Bank. Collier authors and coauthors papers, case studies and presentations on index insurance and weather risk management and assists in the development of GlobalAgRisk funding proposals for innovative agricultural insurance programmes in lower income countries.

Jerry Skees is the H.B. Price Professor of Agricultural Policy and Risk, Department of Agricultural Economics, University of Kentucky. In addition, he is president of GlobalAgRisk, Inc. Dr. Skees has a unique career, blending his experience in academia, government and the private sector to focus on public policy for natural disaster risk in agriculture. Since 1997, he has worked in over 10 emerging or developing economies. Ongoing work includes projects in Mongolia, Peru and Vietnam.

Barry Barnett is president of Acacia Economic Consulting, Inc., a firm that provides agricultural insurance and risk management consulting services to governments, donor organisations and private-sector entities. Barnett has conducted underwriting and actuarial expert reviews for the Risk Management Agency and conducted a World Bank risk assessment for agricultural insurance in China. Dr. Barnett is an associate professor in the Department of Agricultural and Applied Economics, College of Agricultural Economics, Mississippi State University. 